\title{
Endangered Medicinal Plant Polygonatum cirrhifolium (Wall.) Royle Undergoing Erratic Male Meiosis in Kinnaur Population
}

\author{
Kamlesh Kumari* and Manjit Inder Singh Saggoo \\ Department of Botany, Punjabi University, Patiala, 147002, Punjab, India \\ Received December 2, 2016; accepted June 28, 2017
}

\begin{abstract}
Summary Polygonatum cirrhifolium commonly known as Sobnyam in Kinnaur is rich source of starch, pectin, protein and fiber content. In the present study, two accessions of P. cirrhifolium belonging to family Asparagaceae were studied for male meiosis from the cold desert region of Kinnaur. Both the accessions showed the presence of 16 bivalents (based on $x=8$ ) at diakinesis and metaphase, which is in conformity with the previous reports. Earlier, floristic diversity of medicinal and aromatic plants was studied by various workers, but the cytological study along with the meiotic abnormalities in the species has been carried out for the first time from the study area. Therefore, there is need to generate awareness among the local people regarding the conservation and utilization of medicinal plants.
\end{abstract}

Key words Endangered, Wild edible plant, Meiotic irregularities, Ethno medicinal value, Kinnaur, Himachal Pradesh.

Present study was conducted in district Kinnaur, the high altitude area that comes under Trans Himalayan arid zone rich in endemic plants. District Kinnaur in Himachal Pradesh lies between $31^{\circ} 05^{\prime} 50^{\prime \prime}-32^{\circ} 05^{\prime} 15^{\prime \prime} \mathrm{N}$ latitude to $77^{\circ} 45^{\prime}-79^{\circ} 00^{\prime} 35^{\prime \prime} \mathrm{E}$ longitude and cover an area of about $6401 \mathrm{~km}^{2}$. Polygonatum a genus of about 57 species has its centre of diversity in Eastern Himalayas and Western China (Poonam et al. 2011). Around the world found in Northern Asia, China, Nepal, Bhutan, Japan, temperate parts of Eurasia and North America at an elevation of $2000-4000 \mathrm{~m}$. In India the species is occasionally found in the forest and grassy slopes of temperate Himalayas in between 1500-3000 m in Himachal Pradesh, Uttarakhand, Manipur and Sikkim (Balkrishna et al. 2012).

P. cirrhifolium is an erect tall perennial herb growing $60-120 \mathrm{~cm}$ in height. Leaves are narrow lance like, in whorls of three to six, linear $7-12 \mathrm{~cm}$ long, $3-4 \mathrm{~mm}$ wide. Stem is erect, weak and glabrous often climbing by means of tendril like tips of leaves. The flowers are tube shaped borne as drooping clusters from leaf axis with white coloured triangular petals. The fruits are orange red coloured berries when ripe (Fig. 1). The plant grows at an altitude range of $2000-3100 \mathrm{~m}$ in Kinnaur. Polygonatum species have traditional use, both as medicine and food, in China and other countries, like the Northern and Eastern United states, South-Central Canada, India and Korea (Youn et al. 2007, Misra et al.

*Corresponding author, e-mail: ramesh.gunjunegi11@gmail.com DOI: 10.1508/cytologia.82.391
2008).

Cytologically this species revealed intraspecific variability as $2 n=26,28,32,38,56$. Kinnaur exhibit unique, isolated, extreme climatic locations rich in endemic forms. The non-availability of cytological information about taxa from the region promoted us to study this endangered plant.

Earlier the medicinal importance of the plant was studied from Kinnaur (Negi and Chauhan 2009), but the cytological investigation have remained unexplored, so the present study focused on the various irregularities during meiosis in the studied species.

Materials and methods

Plant material was collected from the wild plants growing on open moist slopes around the apple orchards in district Kinnaur, Himachal Pradesh in June-July 2015 and was identified with the help of regional floras and Botanical Survey of India (BSI) Herbarium, Dehradun. The voucher specimens were deposited in the Herbarium, Department of Botany, Punjabi University, Patiala (PUN). For Ethnobotanical uses local amchi and elderly people nearby habitations were consulted. For meiotic studies, the young buds of suitable sizes were fixed in carnoy's fixative for $24 \mathrm{~h}$ and then stored in $70 \%$ alcohol at $4^{\circ} \mathrm{C}$ until use. Anthers were squashed in $2 \%$ acetocarmine and a number of freshly prepared slides were examined. Pollen fertility was estimated through stainability test with glycerol-acetocarmine mixture $(1: 1)$. Well-filled pollen grains with uniformly stained cyto- 


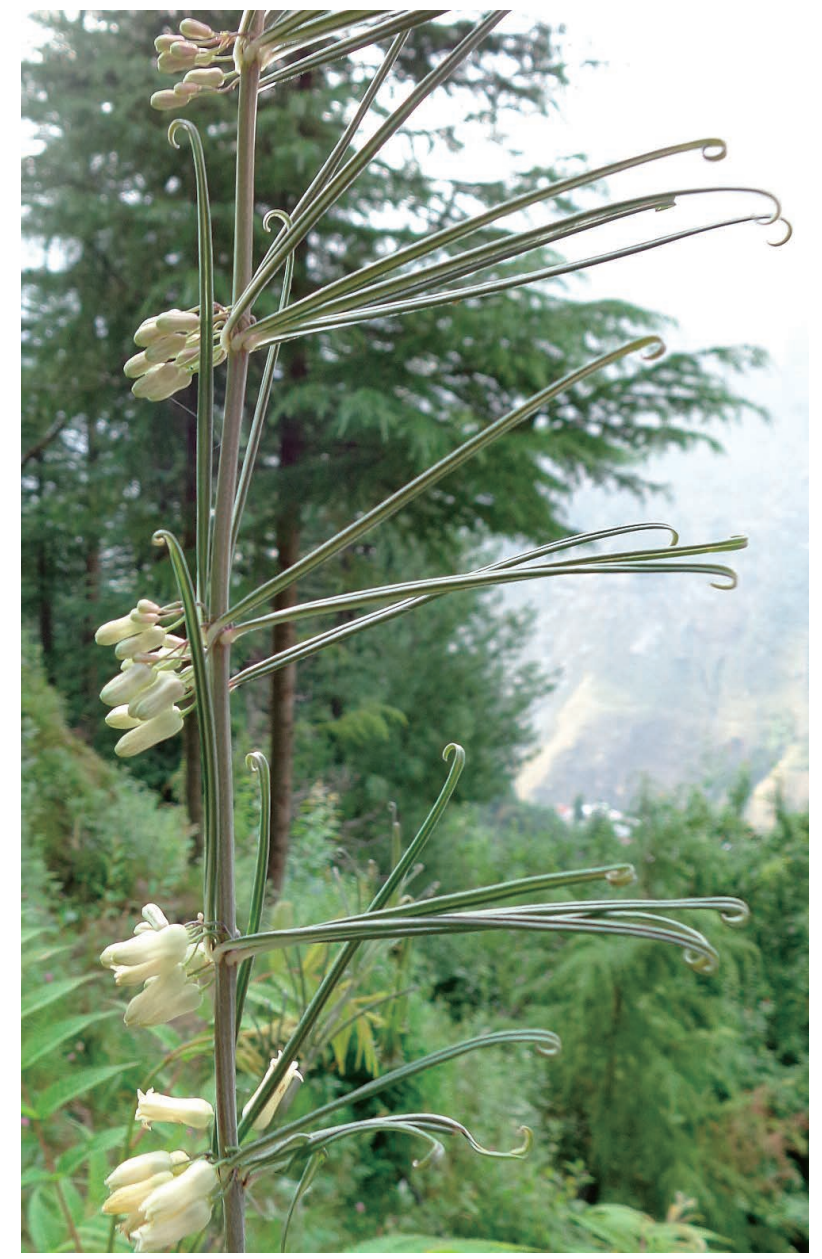

Fig. 1. Polygonatum cirrifolium growing in wild.

plasm were considered fertile while unstained or partially stained was counted as sterile. Photomicrographs were made from the temporary mounts using Nikon $80 \mathrm{i}$ Eclipse Microscope.

\section{Results and discussion}

\section{Medicinal uses}

Traditionally, $P$. cirrhifolium has various medicinal uses. The plant is considered to be wild tasty leafy vegetable and are eaten roasted, young shoots are also added to salads (Wujisguleng et al. 2012). Dried rhizomes and bulbs also show higher protein content, macro and micronutrients such as copper, iron, potassium, calcium and energy value including some fats and fiber content (Sharma et al. 2014).

In Lahaul valley, the plant is useful in the treatment of pain in kidneys and waist region, fluid retention in joints and it restores body strength (Sharma et al. 2011). In Almora district of Uttarakhand, the tubers mixed with water is used for removing weakness, leaves eaten as vegetable, root infusion with milk used as an aphrodisiac and blood purifier, paste made out of its roots is used in healing cuts and wounds, skin irritations and inflammations, when consumed as a tea, it is used to cure wide range of symptoms associated with menopause, indigestion, diabetes, broken bones, insomnia, kidney pains and infertility (Kumari et al. 2012). In Garhwal region, $P$. cirrhifolium is used as a tonic and whole plant is useful in curing skin diseases, wounds, ulcers, fever, cough, bronchitis and general debility. In Parvati valley of Himachal Pradesh, the plant is used in rheumatism, cough and debility from old age (Sharma et al. 2004). In China, the plant has reported to show hypoglycemic, hypertensive, antibacterial and antifungal effects (Singh 2006). Locals in Kinnaur, uses leaves as vegetable, tonic, roots for washing purposes (Negi and Chauhan 2009). Local amchi suggest the powdered roots mixed with milk as tonic, to cure headache, skin irritation, healing burns.

\section{Meiotic study}

In the present study, the species was collected from Nichar $(2150 \mathrm{~m})$ and Kande $(2200 \mathrm{~m})$ villages in Kinnaur valley. Cytological analysis of both the accessions revealed chromosome count of $n=16$ at diakinesis and metaphase-I (Figs. 2A-2B). This confirms the earlier chromosome count reported from Lahaul area of Himachal Pradesh (Lattoo et al. 2005). The present count is tetraploid. Chromosome number already reported in the species are $2 n=26,28$ from North Sikkim, $2 n=38$ from Shimla and $2 n=56$ from China Hill (Kumar 1959a, 1959b, 1960). The detailed meiotic course shows the abnormal behavior in both the populations (Figs. 2C-2N). The population collected from Nichar (PUN-59125) showed the presence of late disjunction at M-I (4.68\%), out of plate bivalents at M-I (7.46\%), chromosome stickiness $(13.20 \%)$, laggards at A-I (12.30\%), and bridges at A-I $(8.33 \%)$ and abnormal microsporogenesis in the form of monad (19.79\%) and dyad (11.11\%). Late disjunction, which is the failure of chromosomes to separate, is generally due to interlocking of chiasmata. The population collected from Kande (PUN-59126) showed the presence of out of plate bivalents at M-I (6.97\%), chromosome stickiness (9.43\%), laggards at A-I (7.69\%), and bridges at T-I (7.14\%). The chromosomal stickiness observed in the species involving intense clustering of chromosomes, may be due to presence of mutant genes (Kaul and Murthy 1985) or abiotic factors such as temperatures (Caetano-Pereira et al. 1995). In both the populations bridges and laggards were observed at A-I and T-I, causes of which may be due to interlocking of bivalents (Bhattacharjee 1953), or paracentric inversion (Sinha and Godward 1972). Further, microsporogenesis was greatly affected with the appearance of monad (17.64\%), dyad (10.34\%), and polyad (7.84\%). Due to these meiotic irregularities, the pollen fertility was also reduced and it varied from 69.44 to $72.60 \%$ (Fig. 2O).

Although the plant is listed as endangered but there is no proper management plan for conservation due to lack of information. The plant is facing multiple threats. 

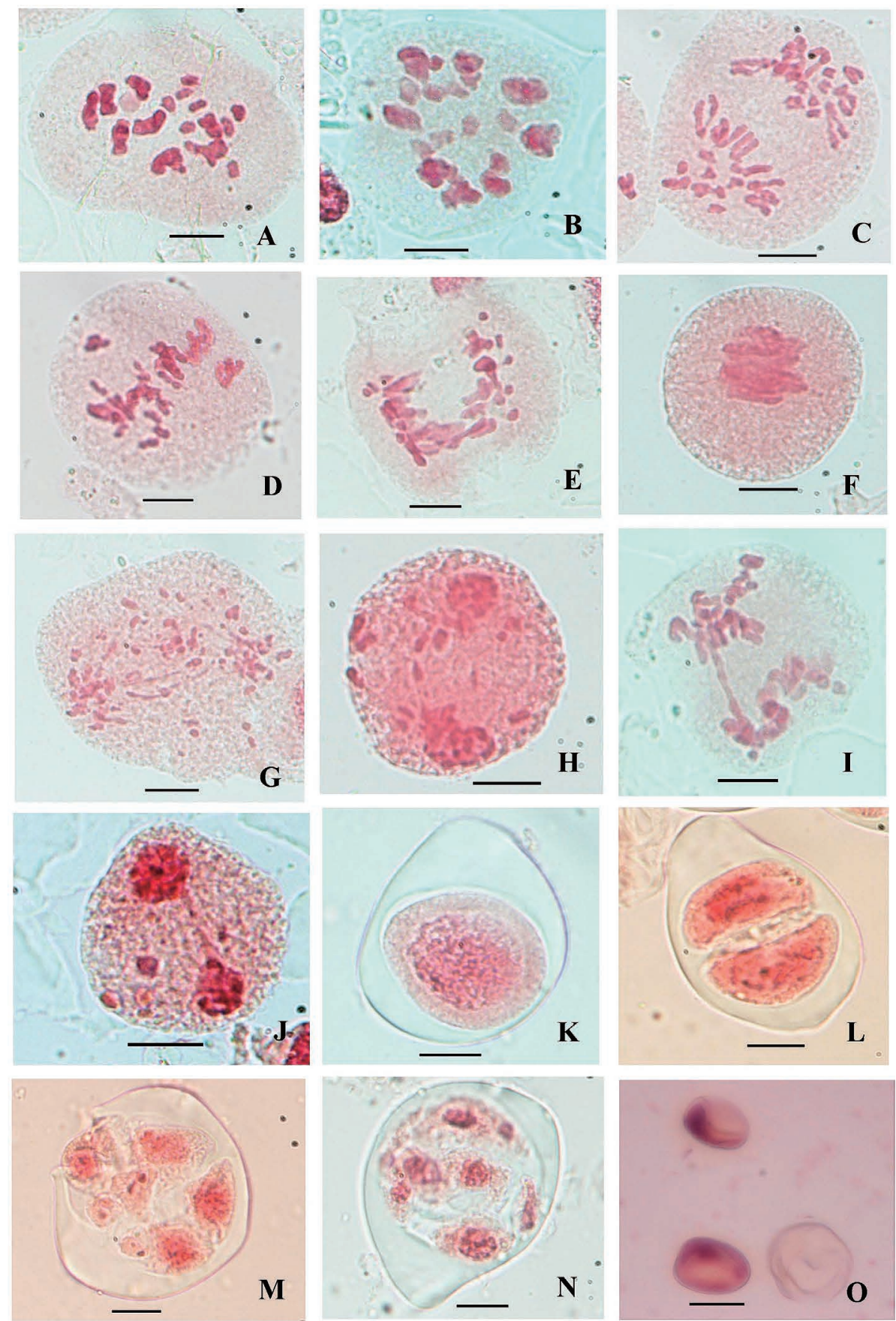

Fig. 2. Polygonatum cirrifolium. A-B) A PMC showing 16 (eight large sized and eight small sized) bivalents at diakinesis and M-I. C) A PMC with 16:16 distribution of chromosomes at A-I. D) Out of plate bivalents at M-I. E) Late disjunction of bivalents at A-I. F) A PMC showing chromosome stickiness at M-I. G-H) A PMC with laggards at A-I and T-I. I-J) A PMC with Bridges at A-I and T-I. K) A PMC with monad. L) A PMC with dyad. M-N) A PMC with polyad. O) Sterile and fertile pollen grains. M-I=metaphase I; A-I=anaphase I. Scale bar $=10 \mu \mathrm{m}$.

The reproductive potential of the wild plants is far from satisfactory. The local inhabitants are overexploiting this plant for medicinal as well as food purpose. The uprooting of plants for rhizome also contributes towards its least availability. The present study emphasize that this medicinal plant is suffering from negligence of people both common man and researchers. Conservation strategies are urgently needed. Such medicinally important plants should be conserved with both in situ and ex situ methods of conservation. The study is useful in under- standing the meiotic behavior in the species, which is the first attempt to work out cytomorphology of the plant from the cold desert region which remained unexplored cytologically. Further, the geographical distribution, cytomorphological diversity and ethnobotanical aspects in the studied medicinal plant, mark out the better chemotypes for further conservation. 


\section{Acknowledgements}

The authors are grateful to the UGC, New Delhi for providing financial assistance under the UGC-BSR Fellowship and DRS SAP III and ASIST programme. We are thankful to the Director Botanical Survey of India, Dehradun for helping in authentication of herbarium samples. Thanks are also due to the Head, Department of Botany, Punjabi University, Patiala for providing all the necessary laboratory facilities.

\section{References}

Balkrishna, A., Srivastava, A., Mishra, R. K., Patel, S. P., Vashistha, R. K., Singh, A., Jadon, V. and Saxena, P. 2012. Astavarga plants-threatened medicinal plants of the North-West Himalaya. Int. J. Med. Aromat. Plants 2: 661-676.

Bhattacharjee, S. K. 1953. Cytogenetics of Lens esculanta Monesch. Caryologia 5: 159-166.

Caetano-Pereira, C. M., Pagliarini, M. S., Brasil, E. M. and Martins, E. N. 1995. Influence of aluminium in causing chromosome stickiness in maize microsporocytes. Maydica 40: 325-330.

Kaul, M. L. and Murthy, T. G. 1985. Mutant genes affecting higher plant meiosis. Theor. Appl. Genet. 70: 449-466.

Kumar, V. 1959a. Karyotype in two Himalayan species of Polygonatum. Experientia 15: 419-420.

Kumar, V. 1959b. Proceedings of the 46th Indian Science Congress, part 3, Kolkata. pp. 19-20.

Kumar, V. 1960. Proceedings of the 47th Indian Science Congress, part 3, Kolkata. p. 370.

Kumari, P., Joshi, G. C. and Tewari, L. M. 2012. Indigenous uses of threatened ethnomedicinal plants used to cure different diseases by ethnic people of Almora district of Western Himalaya. Int. J. Ayurvedic Herb. Med. 2: 661-678.
Lattoo, S. K., Khan, S. and Dhar, A. K. 2005. A new chromosome number in Polygonatum cirrhifolium Royle-An endangered Liliaceous medicinal herb. Curr. Sci. 89: 1080-1081.

Misra, S., Maikhuri, R. K., Kala, C. P., Rao, K. S. and Saxena, K. G. 2008. Wild leafy vegetables: a study of their subsistence dietetic support to the inhabitants of Nanda Devi Biosphere Reserve, India. J. Ethnobiol. Ethnomed. 4: 15.

Negi, V. M. and Chauhan, N. S. 2009. Medicinal and aromatic plants wealth of a tribal district Kinnaur in Himachal Himalayas. Indian Forester 135: 838-852.

Poonam, B., Pratti, P. and Prasad, N. B. 2011. Polygonatum verticillatum (Linn.) All. and Polygonatum cirrhifolium (Wall.) Royle: two threatened vital healers from Asthaverga nurtured by Garhwal Himalaya, India. J. Plant Dev. 18: 159-167.

Sharma, B. D., Singh, L. and Kaur, M. J. 2014. Nutritional Composition of Rare Himalayan Herbs Constituting the World's First Health Food. Int. J. Agri. Food Sci. Tech. 5: 75-80.

Sharma, P. K., Chauhan, N. S. and Lal, B. 2004. Observations on the traditional phytotherapy among the inhabitants of Parvati valley in western Himalaya, India. J. Ethnopharmacol. 92: 167-176

Sharma, P. K., Thakur, S. K., Manuja, S., Rana, R. K., Kumar, P., Sharma, S., Chand, J., Singh, A. and Katoch, K. K. 2011. Observations on Traditional Phytotherapy among the Inhabitants of Lahaul Valley through Amchi System of Medicine-A Cold Desert Area of Himachal Pradesh in North Western Himalayas, India. Chin. Med. 2: 93-102.

Singh, A. P. 2006. Ashtavarga-rare medicinal plants. Ethnobot. Leaflets 10: 104-108.

Sinha, S. S. N. and Godward, M. B. E. 1972. Radiation studies in Lens culinaris. Indian J. Genet. 32: 331-339.

Wujisguleng, W., Liu, Y. and Long, C. 2012. Ethnobotanical review of food uses of Polygonatum (Convallariaceae) in China. Acta Soc. Bot. Pol. 81: 239-244.

Youn, Y. N., Lim, E., Lee, N., Kim, Y. S., Koo, M. S. and Choi, S. Y. 2007. Screening of Korean medicinal plants for possible osteoclastogenesis effects in vitro. Genes Nutr. 2: 375-380. 